\title{
Susceptibility of Escherichia coli isolated from uteri of postpartum dairy cows to antibiotic and environmental bacteriophages. Part II: In vitro antimicrobial activity evaluation of a bacteriophage cocktail and several antibiotics
}

\author{
T. M. A. Santos, ${ }^{*}$ R. O. Gilbert, $\dagger$ L. S. Caixeta, ${ }^{*}$ V. S. Machado, ${ }^{*}$ L. M. Teixeira, $\ddagger$ and R. C. Bicalho ${ }^{* 1}$ \\ *Department of Population Medicine and Diagnostic Sciences, College of Veterinary Medicine, \\ †Department of Clinical Sciences, College of Veterinary Medicine, and \\ ‡Department of Microbiology, College of Agriculture and Life Sciences, Cornell University, Ithaca, NY 14853
}

\begin{abstract}
The use of pathogenic-specific antimicrobials, as proposed by bacteriophage therapy, is expected to reduce the incidence of resistance development. Eighty Escherichia coli isolated from uteri of Holstein dairy cows were phenotypically characterized for antimicrobial resistance to ampicillin, ceftiofur, chloramphenicol, florfenicol, spectinomycin, streptomycin, and tetracycline by broth microdilution method. The lytic activity of a bacteriophage cocktail against all isolates was performed by a similar method. Additionally, the effect of different concentrations of antimicrobials and multiplicities of infections (MOI) of the bacteriophage cocktail on E. coli growth curve was measured. Isolates exhibited resistance to ampicillin $(33.7 \%)$, ceftiofur (1.2\%), chloramphenicol (100\%), and florfenicol $(100 \%)$. All strains were resistant to at least 2 of the antimicrobial agents tested; multidrug resistance $(\geq 3$ of 7 antimicrobials tested) was observed in $35 \%$ of $E$. coli isolates. The major multidrug resistance profile was found for ampicillin-chloramphenicol-florfenicol, which was observed in more than $96.4 \%$ of the multidrug-resistant isolates. The bacteriophage cocktail preparation showed strong antimicrobial activity against multidrugresistant E. coli. Multiplicity of infection as low as $10^{-4}$ affected the growth of the E. coli isolates. The ratio of 10 bacteriophage particles per bacterial cell (MOI $=10^{1}$ ) was efficient in inhibiting at least $50 \%$ of all isolates. Higher MOI should be tested in future in vitro studies to establish ratios that completely inhibit bacterial growth during longer periods. All isolates resistant to florfenicol were resistant to chloramphenicol and, because florfenicol was recently introduced into veterinary clinics, this finding suggests that the selection
\end{abstract}

Received April 15, 2009.

Accepted October 5, 2009.

${ }^{1}$ Corresponding author: rcb28@cornell.edu pressure of chloramphenicol, as well as other antimicrobials, may still play a relevant role in the emergence and dissemination of florfenicol resistance in E. coli. The bacteriophage cocktail had a notable capacity to inhibit the in vitro growth of $E$. coli isolates, and it may be an attractive alternative to conventional treatment of metritis by reducing $E$. coli in uteri of postpartum dairy cows.

Key words: antimicrobial resistance, bacteriophage therapy, dairy cow, metritis

\section{INTRODUCTION}

Metritis is one of the most important disorders in cattle (Melendez et al., 2004). Approximately one-third of postparturient cows develop metritis and 10 to $15 \%$ have clinical endometritis (Borsberry and Dobson, 1989). The consequences of metritis range from a subclinical infection to illness with pyrexia, reduced milk yield, and, occasionally, death. However, subclinical cases of metritis often progress to endometritis, which is an important cause of infertility in cows and economic loss in the dairy industry (Gilbert et al., 2005). High prevalence of subclinical endometritis (53\%) was founded among dairy herds in the United States using cytological methods for the diagnosis of uterine diseases (Gilbert et al., 2005).

Following calving, the uterus of more than $90 \%$ of all cows becomes contaminated with bacteria (Sheldon et al., 2002), some of which are harmful and lead to establishment of infection and uterine disease (Bondurant, 1999). A diversity of bacteria can be isolated from the early postpartum uterus (Sheldon et al., 2004). Escherichia coli and Arcanobacterium pyogenes are the most common bacteria isolated from uterine infection, but other microorganisms such as Fusobacterium necrophorum, Prevotella melaninogenicus, Pseudomonas spp., Streptococcus spp., Staphylococcus spp., and Bacteroides spp. are known to be responsible for puerperal metritis 
(Sheldon et al., 2004). Escherichia coli is usually the most prevalent early postpartum uterine pathogen and almost always precedes other uterine pathogens (Dohmen et al., 2000).

Ideally, therapy for uterine infection should control pathogens from the uterus and should result in withdrawal periods for milk and meat that are as short as possible (Azawi, 2008). Although systemic or intrauterine antibiotic therapy is commonly used as the treatment for metritis (Azawi, 2008), it is recognized that antibiotic therapy cannot sterilize the uterus nor prevent recontamination that occurs during the early postpartum weeks (Sheldon and Dobson, 2004; Azawi, 2008). Furthermore, widespread usage of antimicrobials in food animal production has contributed to the emergence of antimicrobial resistance among pathogens, which complicates the treatment of infectious diseases (Tollefson et al., 1999).

The increasing level of resistance to frontline antimicrobial agents relevant to the treatment of human diseases is a significant public health concern (Tollefson and Miller, 2000) and has led to important changes in the perceptions and priorities of federal agencies with regard to usage of antimicrobials as growth promoters and prophylactic agents (Angulo et al., 2004). The FDA, USDA, and Centers for Disease Control and Prevention (CDC) strongly promote the development of new classes of antimicrobials and other products able to eliminate or reduce risk of bacterial resistance (CDC, 2006). The use of pathogenic-specific antimicrobials is expected to reduce the incidence of resistance development (Walsh, 2003).

Bacteriophage therapy, which uses virulent (lytic) bacteriophages to control bacterial growth, has shown to be an attractive alternative to conventional drugs (Viscardi et al., 2008) and has been successful in animal trials against a broad range of bacterial pathogens such as enteropathogenic E. coli (Callaway et al., 2008), Pseudomonas aeruginosa (Soothill, 1992), Staphylococcus aureus (Matsuzaki et al., 2003), Acinetobacter baumannii (Soothill, 1992), and vancomycin-resistant Enterococcus faecium (Biswas et al., 2002). We previously isolated bacteriophages from environmental samples of 2 large commercial dairy farms using wild strains of E. coli from uteri of postpartum dairy cows as hosts (Bicalho et al., 2010) and tested the lytic activity to compose a broad-spectrum bacteriophage cocktail to be used in the control of $E$. coli in the uterus in a future clinical trial experiment.

The objective of the present study was to investigate antimicrobial resistance profiles of $E$. coli isolated from uteri of postpartum Holstein dairy cows and to evaluate the effect of the inoculation of several different multiplicities of infections of a bacteriophage cocktail on the growth curve of $E$. coli isolates.

\section{MATERIALS AND METHODS}

\section{Bacterial Strains and Culture Conditions}

Eighty E. coli isolates were taken from a collection of likely commensal, nonpathogenic strains and some pathogenic strains obtained from uterine secretions of Holstein dairy cows (Bicalho et al., 2010). Briefly, uterine secretion was collected and diluted in $0.9 \%$ saline solution ( $\mathrm{pH}$ 7.0) and the sample was aerobically cultured on MacConkey agar (Difco, Becton and Dickinson, Franklin Lakes, NJ) at $37^{\circ} \mathrm{C}$. Escherichia coli colonies were distinguished by a purple-red color. Typical E. coli colonies were streaked on Chromagar E.coli (Paris, France) for confirmation and further isolation. Colony morphology and characteristic appearance in smears stained by Gram's method were used to examine purity. Additionally, a 340-bp fragment of the bacterial $16 \mathrm{~S}$ rRNA-encoding gene was amplified and genetic diversity of $E$. coli isolates was evaluated by randomly amplified polymorphic DNA-PCR (Bicalho et al., 2010). Phylogenetic grouping was performed by triplex PCR, which uses a combination of 2 genes (chuA and yjaA) and an anonymous DNA fragment (Clermont et al., 2000). A stock of all 80 isolates obtained was kept at $-80^{\circ} \mathrm{C}$ in Luria-Bertani broth (Difco) containing $20 \%$ glycerol for further testing.

\section{Bacteriophage Propagation}

Bacteriophages, isolated from the manure lagoons of 2 large commercial dairy farms located near Ithaca, New York (Bicalho et al., 2010), were routinely propagated on E. coli strains originally used as host during the bacteriophage isolation. High-titer stocks for each bacteriophage preparation that compounded the cocktail were prepared in SM buffer $(100 \mathrm{mM} \mathrm{NaCl}, 8$ $\mathrm{mM} \mathrm{MgSO}$, $1 M$ Tris-HCl; pH 7.5) by the plate lysate method (Sambrook and Russell, 2001). To remove debris, the lysate obtained from the top agar was pooled and centrifuged at $10,000 \times \mathrm{g}$ at $4^{\circ} \mathrm{C}$ for $10 \mathrm{~min}$ and the supernatant was sterilized by filtering through a filter with a $0.22-\mu \mathrm{m}$ pore size. These high titer stocks were used to compound the cocktail and determine the minimum inhibitory multiplicities of infections (MOI) of bacteriophage particles.

\section{Antimicrobial Susceptibility Assay}

Prior to MIC determinations, all 80 isolates were revived by subculture on Mueller-Hinton broth and in- 
cubated for 8 to $12 \mathrm{~h}$ at $37^{\circ} \mathrm{C}$. The MIC determinations were performed by broth microdilution method as described by the Clinical and Laboratory Standards Institute (CLSI, 2008) recommendations. The tests consisted of manually prepared 96 -well microtiter plates containing the following 7 antimicrobials (Sigma-Aldrich, St. Louis, MO): ampicillin, ceftiofur, chloramphenicol, florfenicol, spectinomycin, streptomycin, and tetracycline. The dilutions for each antimicrobial tested ranged from $0.25 \mu \mathrm{g} / \mathrm{mL}$ to $256 \mu \mathrm{g} / \mathrm{mL}$ for all the antibiotics, and all tests were performed in duplicate. The cultures were diluted in Mueller-Hinton broth to $10^{5} \mathrm{cfu} / \mathrm{mL}$ and an aliquot of $200 \mu \mathrm{L}$ of the diluted culture was added to microtiter plate wells containing various concentrations of the antimicrobials, to a total volume of $300 \mu \mathrm{L} /$ well. The assays were carried out in duplicate. The controls of adequacy of the broth to support bacterial growth and of sterility of the broth were done.

The MIC was determined based on CLSI (2008) guidelines for the manually prepared panels after 18 $\mathrm{h}$ of incubation at $37^{\circ} \mathrm{C}$ under aerobic conditions, and the first dilution with no visible growth was considered the MIC for each strain. In addition to the uterine $E$. coli isolates tested, the reference strain of E. coli ATCC 25922 was included as quality control for MIC determination, as recommended by CLSI (2008). The MIC that inhibited at least $50 \%\left(\mathbf{M I C}_{50}\right)$ and at least $90 \%$ $\left(\mathbf{M I C}_{\mathbf{9 0}}\right)$ of the isolates, as well as the minimum and maximum MIC, were also derived.

Additionally, in parallel with the CLSI (2008) standard test, MIC for 57 isolates was determined by spectrophotometric measurement of the bacterial growth (Moreira et al., 2005). Growth was periodically assessed spectrophotometrically in a microplate reader (Synergy 2, BioTek, Winooski, VT) at $600 \mathrm{~nm}$. Curves were plotted with the average of the duplicate assays. The results of this kinetic test were statistically analyzed to derive the mean optical density at $600 \mathrm{~nm}\left(\mathbf{O D}_{600}\right)$ of all isolates, in all concentrations, and for each antimicrobial tested.

\section{Bacterial Challenge Test-Bacteriophage Cocktail Assay}

A bacteriophage cocktail composed of bacteriophages isolated from the manure lagoons of 2 large commercial dairy farms located near Ithaca, New York (Bicalho et al., 2010) was used to test the susceptibility of all $80 \mathrm{E}$. coli isolates and determine the minimum inhibitory MOI of the bacterial isolates for the bacteriophage cocktail. All 80 isolates were cultured on Mueller-Hinton broth and incubated for 8 to $12 \mathrm{~h}$ at $37^{\circ} \mathrm{C}$. The cultures were diluted in Mueller-Hinton broth to $10^{5} \mathrm{cfu} / \mathrm{mL}$ and the challenge tests were performed in manually prepared 96-well microtiter plates containing different dilutions of the bacteriophage cocktail to reach ratios ranging from $10^{-4}$ to $10^{2} \mathrm{pfu} / \mathrm{cfu}$ in wells containing $10^{4} \mathrm{cfu}$ of $E$. coli. The assays were carried out in duplicate, and the required controls of adequacy of the broth to support the growth of the microorganism and of sterility of the broth were done.

Minimum inhibitory MOI was determined after $18 \mathrm{~h}$ of incubation at $37^{\circ} \mathrm{C}$ under aerobic conditions, and the first ratio with no visible growth was considered the minimum inhibitory MOI for each strain. The $\mathrm{MOI}_{50}$ and $\mathrm{MOI}_{90}$, as well as the minimum and maximum MOI, were also derived. Additionally, minimum MOI for 57 isolates was determined by measurement of the bacterial growth. In this case, growth was periodically assessed spectrophotometrically in a microplate reader (Synergy 2, BioTek) at $600 \mathrm{~nm}$. Curves were plotted with the average of the duplicate assays. The results of this kinetic test were statistically analyzed to derive the mean $\mathrm{OD}_{600}$ of all isolates and all different MOI.

\section{Data Management and Statistical Analysis}

A general linear mixed model was used to analyze the effect of the different antibiotic concentrations and bacteriophage MOI on the growth curve of $57 \mathrm{E}$. coli isolates and determine the mean values. The outcome variable was the $\mathrm{OD}_{600}$ of the Mueller-Hinton broth culture, which was modeled as a Gaussian (normally distributed data) variable. The assumption that the residuals were normally distributed was satisfied by visually evaluating the distribution plot of the studentized residuals. The independent variables offered to the model were treatment (the bacteriophage cocktail and all antimicrobials tested) and time (from 1 until $10 \mathrm{~h}$ ). The interaction of treatment and time was also included in the model. The data were longitudinally collected and therefore had a series of repeated measures (total of 10) of optical density throughout the study period. This implies that data points were correlated within each $E$. coli isolate. To account appropriately for within- $E$. coli correlation of the optical density, the error term was modeled by imposing a first-order autoregressive covariance structure. Variables and interaction were considered significant when their $P$-values were $<0.05$.

\section{RESULTS}

\section{Bacterial Isolation and Characterization}

All 80 isolated strains were confirmed to be $E$. coli by both cultural methods using chromogenic agar (Chromagar E.coli) and ribosomal DNA amplification. 
Randomly amplified polymorphic DNA-PCR showed 16 different banding pattern profiles for the isolates, 6 of which were observed to be unique, indicating relative diversity between the isolates (Bicalho et al., 2010). Phylogenetic grouping based on triplex PCR showed that all isolates of $E$. coli belonged to phylogroup B1, which generally includes both commensal nonpathogenic and some pathogenic E. coli strains (Smith et al., 2007). Furthermore, isolates from phylogroup B1 typically lack the specialized virulence determinants found in pathogenic strains that cause intestinal or extraintestinal diseases (Picard et al., 1999). Although E. coli belonging to phylogroup B1 are not usually considered to be pathogenic strains, these strains can acquire virulence factors by horizontal transfer, enabling them to become virulent and invade an immunocompromised host (Picard and Goullet, 1988) from the host's reservoir.

\section{Antimicrobial Resistance Patterns in E. coli Isolated from Uterine Fluid}

Interpretation of the MIC based on CLSI (2008) criteria for the isolates of $E$. coli from this study allowed us to conclude that, based on interpretative standard breakpoints for veterinary pathogens, $33.7 \%$ of the isolates were resistant to ampicillin, $1.2 \%$ were resistant to ceftiofur, and $100 \%$ were resistant to chloramphenicol and to florfenicol (Table 1). The $\mathrm{MIC}_{50}$ and the $\mathrm{MIC}_{90}$ for ampicillin were 16 and $32 \mu \mathrm{g} / \mathrm{mL}$, respectively (Table 1). Almost all isolates $(98.7 \%)$ were susceptible to ceftiofur, although this antimicrobial showed the broadest range of $\mathrm{MIC}$. The $\mathrm{MIC}_{50}$ and the $\mathrm{MIC}_{90}$ for ceftiofur were both $1 \mu \mathrm{g} / \mathrm{mL}$ (Table 1). No susceptibility was found to chloramphenicol and florfenicol. The $\mathrm{MIC}_{50}$ and $\mathrm{MIC}_{90}$ for chloramphenicol were $64 \mu \mathrm{g} /$ $\mathrm{mL}$ and $128 \mu \mathrm{g} / \mathrm{mL}$, respectively, and the $\mathrm{MIC}_{50}$ and $\mathrm{MIC}_{90}$ for florfenicol were both $16 \mu \mathrm{g} / \mathrm{mL}$ (Table 1). Among the antimicrobial agents tested, spectinomycin $\left(\mathrm{MIC}_{50}=32 \mu \mathrm{g} / \mathrm{mL} ; \mathrm{MIC}_{90}=64 \mu \mathrm{g} / \mathrm{mL}\right)$, streptomy$\operatorname{cin}\left(\mathrm{MIC}_{50}=8 \mu \mathrm{g} / \mathrm{mL} ; \mathrm{MIC}_{90}=8 \mu \mathrm{g} / \mathrm{mL}\right)$, and tetracycline $\left(\mathrm{MIC}_{50}=1 \mu \mathrm{g} / \mathrm{mL} ; \mathrm{MIC}_{90}=2 \mu \mathrm{g} / \mathrm{mL}\right)$ had excellent activity against the $E$. coli isolates from this study, whereas none of them were resistant to these antimicrobials. Of the 80 isolates tested, all strains were resistant to at least 2 of the antimicrobial agents tested, and multidrug resistance (higher or equal to 3 of 7 antimicrobials tested) was observed in $35 \%$ of the $E$. coli isolates. The major multidrug resistance profile was found for ampicillin-chloramphenicol-florfenicol, which was observed in more than $96.4 \%$ of the multidrug-resistant isolates.

\section{In Vitro Antimicrobial Activity of Bacteriophage Cocktail Against Antimicrobial Multidrug-Resistant E. coli}

The bacteriophage cocktail preparation previously defined (Bicalho et al., 2010) showed efficient antimicrobial activity against antimicrobial multidrug-resistant E. coli from uterine secretion from Holstein dairy cows (Table 2). Multiplicity of infection as low as $10^{-4}$ affected the growth of $1.25 \%$ of the E. coli isolates (Table 2 ). The $\mathrm{MOI}_{50}$ found for the bacteriophage cocktail was $10^{1} \mathrm{pfu} / \mathrm{cfu}$ (Table 2), which means that the ratio of 10 bacteriophage particles from the bacteriophage cocktail per bacterial cell was efficient in inhibiting at least $50 \%$ of the isolates. The $\mathrm{MOI}_{90}$ for the cocktail was $>10^{2}$ $\mathrm{pfu} / \mathrm{cfu}$ (Table 2).

\section{Measurement of Antimicrobial and Bacteriophage Cocktail Effect on the Growth Curve of E. coli}

The MOI of $10^{2}$ was standardized to define the composition of the bacteriophage cocktail and showed excellent effect in inhibiting bacterial growth (Bicalho et al., 2010). Growth of all E. coli isolates was tested in different MOI (Figure 1). It was possible to observe the dose response related to the different plaque-forming unit:colony-forming unit ratios.

All antimicrobial agents tested had a significantly smaller mean $\mathrm{OD}_{600}$ when compared with the control (Table 3). Additionally, a consistent dose effect of the different antimicrobial agents on the mean growth curves was clearly observed: the mean $\mathrm{OD}_{600}$ decreased as the antimicrobial agent dosage increased (Figure 2a, Figure 2b). The bacteriophage cocktail and all antimicrobials tested significantly decreased the mean $\mathrm{OD}_{600}$ when compared with the controls (Table 3). Among the antibiotics tested, ceftiofur and tetracycline were the most effective in inhibiting bacterial growth; the mean $\mathrm{OD}_{600}$ was 0.05 (95\% confidence interval $\left.=0.04-0.06\right)$ for both. The bacteriophage cocktail significantly inhibited bacterial growth in all MOI tested when compared with the control $(95 \%$ confidence interval $=0.27-0.35$; Figure 3; Table 3). Mean $\mathrm{OD}_{600}$ for MOI ranging from $10^{-1}$ to $10^{2}$ were inferior to 0.01 .

\section{DISCUSSION}

During the past decade, the threat of antimicrobial resistance and its global dimensions have been increasingly recognized (Tollefson and Miller, 2000). The use of antimicrobials as growth promoters or prophylactic agents in animal agriculture may be a partial cause of 
the rise of antimicrobial resistance. The high level of resistance to multiple antimicrobials can lead to serious public health problems (Tollefson et al., 1999; Tollefson and Miller, 2000). Escherichia coli is one of the most common bacteria isolated from uterine infection and is known to be responsible for puerperal metritis (Sheldon and Dobson, 2004). Antimicrobial resistance of E. coli from uterine fluid of postpartum dairy cows has been poorly described in the literature. Few studies have reported the antimicrobial activity of various agents against microorganisms isolated from uteri of dairy cows (Sheldon and Dobson, 2004).

Ampicillin, a $\beta$-lactam that belongs to the broadspectrum group of the penicillins, is widely used in human and veterinary medicine. Resistance to $\beta$-lactam antimicrobial agents in $E$. coli is primarily mediated by $\beta$-lactamases, which hydrolyze the $\beta$-lactam ring inactivating the antibiotic (Livermore, 1995). Many different $\beta$-lactamases have been described in ampicillin-resistant E. coli (Livermore, 1995). As shown in Table 1, almost $34 \%$ of the $E$. coli isolates showed resistance to ampicillin. Various levels of ampicillin resistance have been reported in studies of $E$. coli from calves. Sawant et al. (2007) reported the occurrence of $48 \%$ of ampicillinresistant $E$. coli from feces of healthy lactating dairy calves.

Ceftiofur, which is an extended-spectrum cephalosporin that belongs to the class of $\beta$-lactam, is commonly used as a treatment of metritis and other bacterial diseases such as pneumonia and foot rot. The most common mechanism of cephalosporin resistance is also through production of $\beta$-lactamases, although extended-spectrum cephalosporins, like ceftiofur, have increased ring stability against some $\beta$-lactamases (Livermore, 1995). Of all E. coli isolates, $1.25 \%$ showed resistance to ceftiofur (Table 1). A possible mechanism for this resistance is the presence of cephamycinases, coded by the $b l a_{\mathrm{CMY} 2}$ gene, which share extensive homology to chromosomal amp $C \beta$-lactamases (Winokur et al., 2001). Various levels of ceftiofur resistance have been reported in studies of $E$. coli from calves. White et al. (2000) reported the occurrence of $69 \%$ of ceftiofurresistant $E$. coli from diarrheic calves, whereas lower prevalence rates of 11\% (Bradford et al., 1999) and 13\% (Sawant et al., 2007) have been also reported.

All isolates were resistant to chloramphenicol, and $1.25 \%$ were resistant to the higher concentration $(\geq 254$ $\mu \mathrm{g} / \mathrm{mL}$ ) tested (Table 1). Chloramphenicol is a broadspectrum antibiotic that was extensively used in veterinary medicine until the 1980s, when concerns over its toxicity emerged (Settepani, 1984). Resistance to chloramphenicol is well characterized in gram-negative bacteria and is commonly mediated either through enzymatic inactivation of the drug or by chlorampheni- 


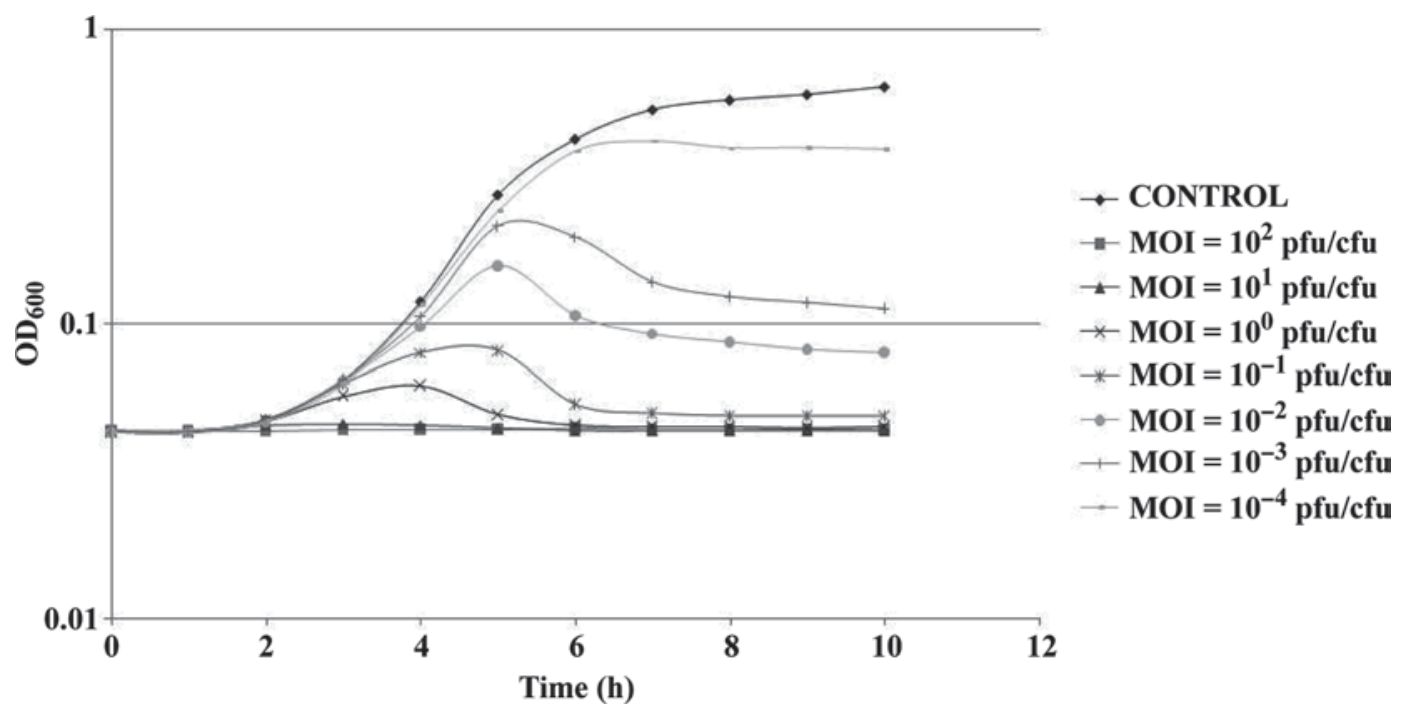

Figure 1. Effect of bacteriophage cocktail on growth curve of a single Escherichia coli isolate exemplifying the typical kinetics of growth and dose response effect observed across all isolates. The minimum multiplicities of infections (MOI), arbitrarily defined as the minimum MOI that completely inhibited growth of the cells for 2 to $3 \mathrm{~h}$ after the beginning of the stationary phase of the control, was $10^{-1}$. OD ${ }_{600}=$ optical density at $600 \mathrm{~nm}$.

col acetyltransferases (CAT; Schwarz et al., 2004), or nonenzymatically mediated through active efflux of chloramphenicol by simple or multidrug efflux systems (Moreira et al., 2005). Resistance to chloramphenicol as observed in this study was particularly interesting because the use of this drug in food animals was banned by the FDA in the 1980s (Gilmore, 1986). However, chloramphenicol resistance likely persisted because of coselection, which occurs with transmission of linked antimicrobial resistance genes on plasmids, transposons, and integrons (Bennett, 2008).

Florfenicol, a fluorinated structural analog of chloramphenicol, was approved for veterinary use in food animals by the FDA in 1996 for treatment of bovine respiratory pathogens. Three florfenicol resistance genes, $c f r, f e x A$, and floR, which also mediate resistance to chloramphenicol, have been described (Schwarz et al., 2004). Florfenicol resistance mediated by the floR gene, which is a homolog of the chloramphenicol resistance efflux gene $c m l A$ (Arcangioli et al., 2000) and which codes a chloramphenicol-florfenicol exporter, has been identified in various gram-negative bacteria, including E. coli. As observed for chloramphenicol, all E. coli isolates in this study also showed resistance to florfenicol (Table 1).

It is known that the structural modifications to form florfenicol from chloramphenicol rendered bacterial resistance to florfenicol through inactivation by CAT enzymes and, consequently, chloramphenicol-resistant strains, in which resistance is based exclusively on CAT activity, are susceptible to florfenicol (Schwarz et al., 2004). Furthermore, multidrug efflux system, which is widely distributed among bacteria, can pump out a wide range of compounds that may have few structural similarities. Therefore, resistance caused by flo $R$ gene, which mediates combined resistance to florfenicol and chloramphenicol by efflux of the drug, should explain the strong associations between chloramphenicol and florfenicol resistance profile found here. However, further molecular study of these isolates is required to confirm this hypothesis. A similar incidence of cross-resistance has been reported in a study that showed $85 \%$ of $E$.

Table 2. Summary of minimum inhibitory multiplicity of infection (MOI; pfu/cfu) of the bacteriophage cocktail for Escherichia coli recovered from uterine secretions of Holstein dairy cows $(\mathrm{n}=80 \text { isolates })^{1}$

\begin{tabular}{|c|c|c|c|c|c|c|c|c|c|c|c|c|}
\hline Item & \multicolumn{8}{|c|}{ Distribution of isolates (\%) } & Minimum MOI & $\mathrm{MOI}_{50}$ & $\mathrm{MOI}_{90}$ & Maximum MOI \\
\hline Bacteriophage cocktail & 1.2 & 13.7 & 13.7 & 11.2 & 6.2 & 11.2 & 5.0 & 37.5 & $10^{-4}$ & $10^{1}$ & $>10^{2}$ & $>10^{2}$ \\
\hline
\end{tabular}

${ }^{1} \mathrm{MOI}_{50}=$ the multiplicity of infection (MOI) that inhibited at least $50 \%$ of the isolates; $\mathrm{MOI}_{90}=$ the MOI that inhibited at least $90 \%$ of the isolates. 

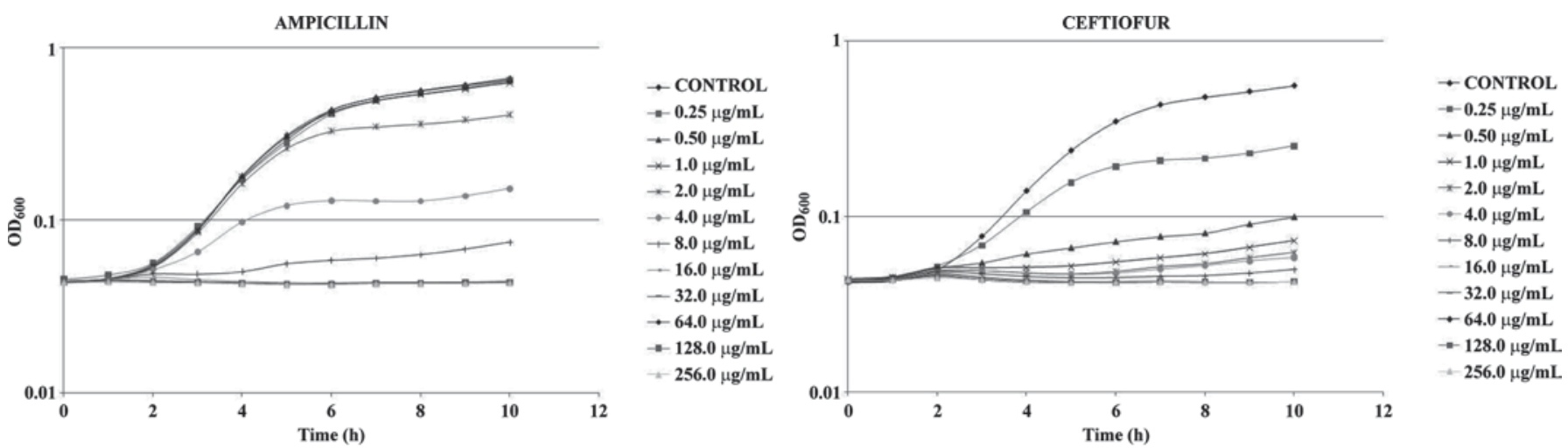

CHLORAMPHENICOL
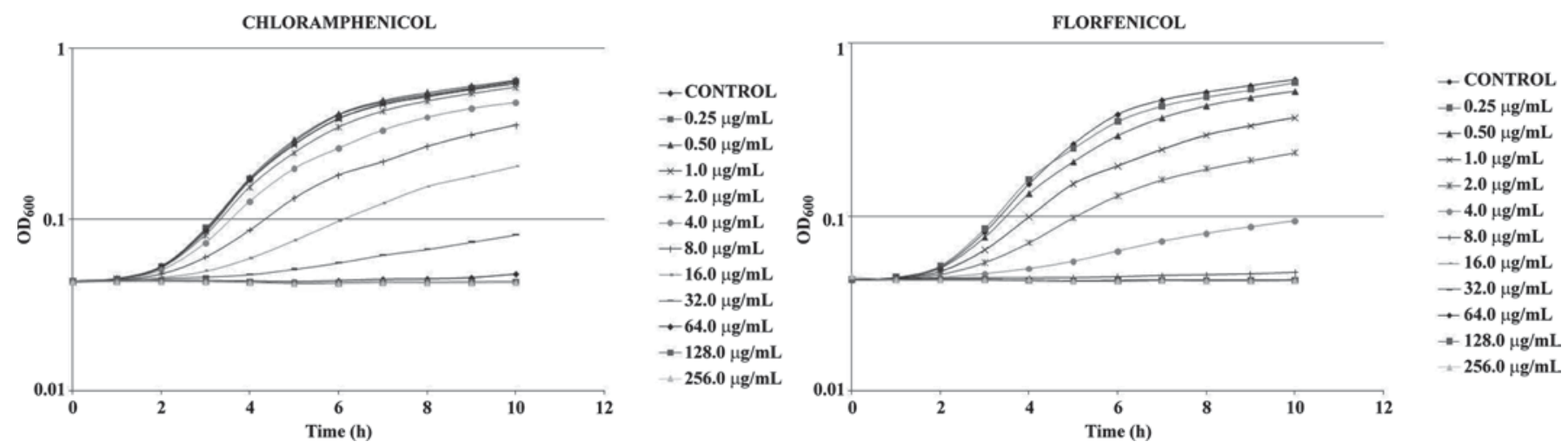

Figure 2a. Effect of antibiotics on growth of Escherichia coli isolated from uteri of postpartum Holstein dairy cows. $\mathrm{OD}_{600}=$ optical density at $600 \mathrm{~nm}$.

Table 3. Mean $\mathrm{OD}_{600}$ for Escherichia coli $\left(\mathrm{n}=80\right.$ isolates) growth curve during $10 \mathrm{~h}$ at $37^{\circ} \mathrm{C}$ under aerobic conditions in Mueller-Hinton broth treated with 7 antimicrobials and 1 bacteriophage cocktail [multiplicity of infection (MOI) ranging from $10^{-4}$ to $\left.10^{2} \mathrm{pfu} / \mathrm{cfu}\right]$

\begin{tabular}{|c|c|c|c|c|c|}
\hline \multirow[b]{2}{*}{ Treatment } & \multicolumn{2}{|c|}{$\% \mathrm{OD}_{600}{ }^{1}$} & \multirow[b]{2}{*}{ Mean $\mathrm{OD}_{600}$} & \multirow[b]{2}{*}{$\mathrm{SE}$} & \multirow[b]{2}{*}{$95 \% \mathrm{CI}^{2}$} \\
\hline & $\leq 0.1$ & $\leq 0.2$ & & & \\
\hline \multicolumn{6}{|l|}{ Antimicrobial } \\
\hline Ampicillin & & & 0.14 & 0.002 & $0.13-0.15$ \\
\hline Ceftiofur & & & 0.05 & 0.002 & $0.04-0.06$ \\
\hline Chloramphenicol & & & 0.18 & 0.002 & $0.16-0.19$ \\
\hline Florfenicol & & & 0.10 & 0.002 & $0.09-0.11$ \\
\hline Spectinomycin & & & 0.17 & 0.002 & $0.16-0.18$ \\
\hline Streptomycin & & & 0.11 & 0.002 & $0.10-0.12$ \\
\hline Tetracycline & & & 0.05 & 0.002 & $0.04-0.06$ \\
\hline Control & & & 0.29 & 0.002 & $0.29-0.30$ \\
\hline \multicolumn{6}{|c|}{ Bacteriophage cocktail } \\
\hline $\mathrm{MOI}=10^{-4}$ & 17.5 & 40.4 & 0.19 & 0.02 & $0.16-0.23$ \\
\hline MOI $=10^{-3}$ & 31.6 & 61.4 & 0.15 & 0.02 & $0.11-0.19$ \\
\hline $\mathrm{MOI}=10^{-2}$ & 54.4 & 59.6 & 0.14 & 0.02 & $0.10-0.18$ \\
\hline $\mathrm{MOI}=10^{-1}$ & 66.7 & 75.4 & 0.09 & 0.02 & $0.06-0.13$ \\
\hline $\mathrm{MOI}=10^{0}$ & 68.4 & 84.2 & 0.07 & 0.02 & $0.04-0.11$ \\
\hline $\mathrm{MOI}=10^{1}$ & 78.9 & 84.2 & 0.06 & 0.02 & $0.03-0.09$ \\
\hline $\mathrm{MOI}=10^{2}$ & 78.9 & 84.2 & 0.05 & 0.02 & $0.02-0.09$ \\
\hline Control & 0.0 & 0.0 & 0.31 & 0.02 & $0.27-0.35$ \\
\hline
\end{tabular}

${ }^{1} \mathrm{OD}_{600}=$ optical density at $600 \mathrm{~nm} ; \mathrm{OD}_{600} \leq 0.1=$ percent of isolates that had an $\mathrm{OD}_{600}$ equal to or smaller than 0.1 at the end of the growth curve study. $\mathrm{OD}_{600} \leq 0.2=$ percent of isolates that had an $\mathrm{OD}_{600}$ equal to or smaller than 0.2 at the end of the growth curve study.

${ }^{2} 95 \%$ CI $=95 \%$ confidence interval. 

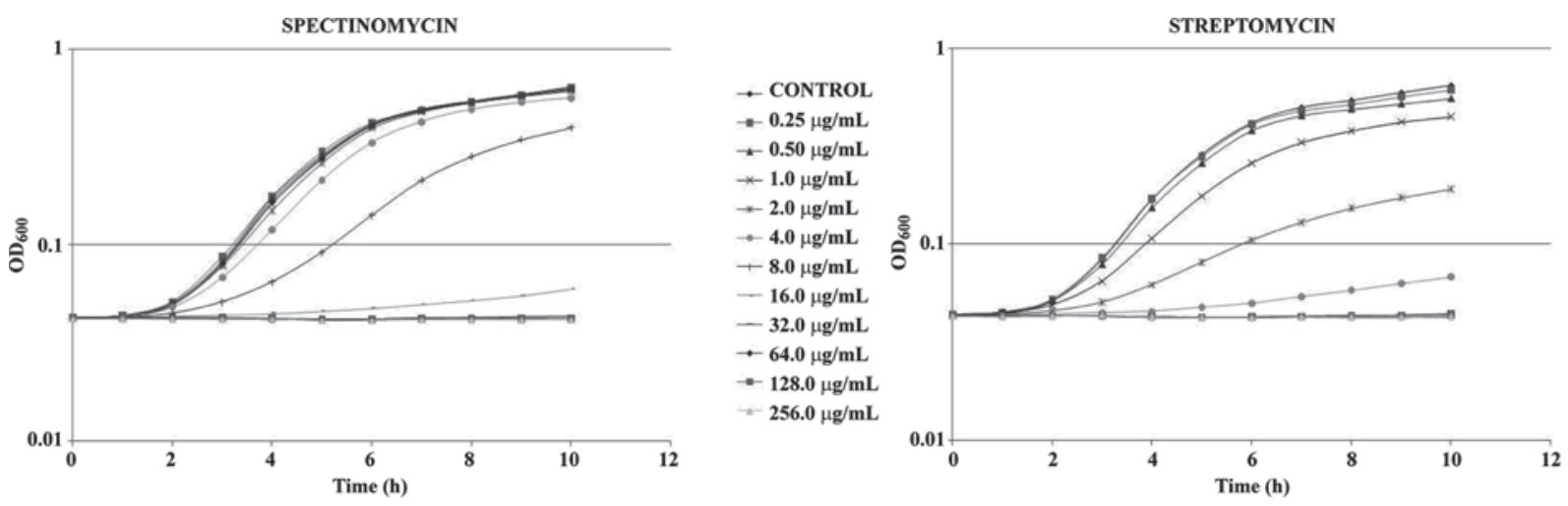

$\rightarrow$ CONTROL

$\rightarrow-0.25 \mu \mathrm{g} / \mathrm{mL}$

$+0.50 \mu \mathrm{g} / \mathrm{mL}$

$-1.0 \mu \mathrm{g} / \mathrm{mL}$

* $2.0 \mu \mathrm{g} / \mathrm{mL}$

$\rightarrow-4.0 \mu \mathrm{g} / \mathrm{mL}$

$+8.0 \mu \mathrm{g} / \mathrm{mL}$

$-16.0 \mu \mathrm{g} / \mathrm{mL}$

$-32.0 \mu \mathrm{g} / \mathrm{mL}$

$\rightarrow 64.0 \mu \mathrm{g} / \mathrm{mL}$

- $128.0 \mu \mathrm{g} / \mathrm{mL}$

$+256.0 \mu \mathrm{g} / \mathrm{mL}$
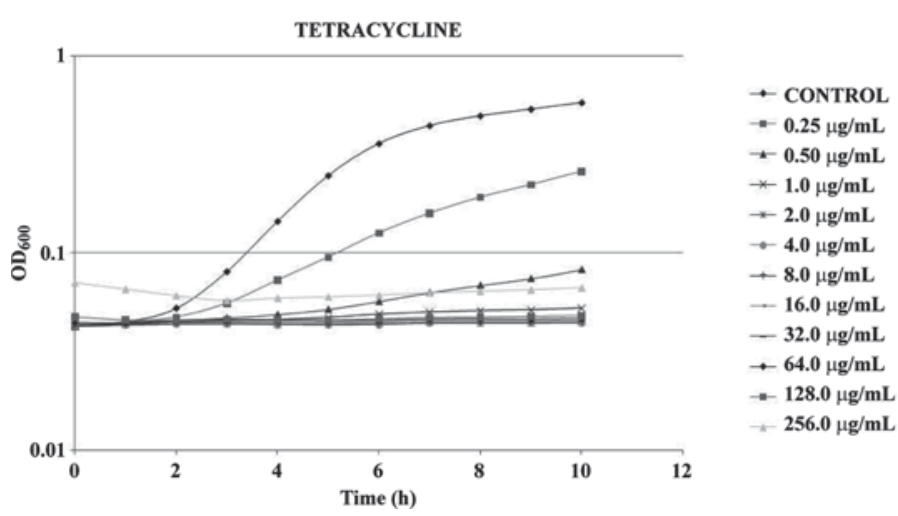

Figure 2b. Effect of antibiotics on growth of Escherichia coli isolated from uteri of postpartum Holstein dairy cows. OD $600=$ optical density at $600 \mathrm{~nm}$.

coli isolates from diarrheic dairy calves were resistant to both florfenicol and chloramphenicol (White et al., 2000).

Escherichia coli is one of the most important known cattle metritis pathogens (Sheldon and Dobson, 2004). In our study, E. coli isolated from uterine secretion from Holstein dairy cows showed multidrug resistance (35\%), and the major profile observed $(96.4 \%)$ was ampicillinchloramphenicol-florfenicol. Mobile genetic elements, such as plasmids, transposons, and integrons, are known to underlie much of the maintenance and spreading of antimicrobial-resistance determinants (Bennett, 2008). Furthermore, some studies showed that E. coli and Salmonella spp. isolates from animals and humans had the same antimicrobial resistance determinants (Fey et al., 2000; Maidhof et al., 2002). The use of antibiotics in food animals could be associated with the selection of antibiotic resistance mechanisms in pathogenic and nonpathogenic isolates of E. coli. Hence, prudent use of antibiotics in veterinary medicine is highly recommended.

The growing concern about the rise of multidrugresistant bacteria in humans and animals has revamped the interest in bacteriophage therapy research. Bacteriophages have been successfully used in animal trials against a broad range of pathogenic E. coli (Brussow, 2005). Bovine metritis is likely to be successfully treated with bacteriophage therapy because of the following reasons: an abundance of polyvalent environmental bacteriophages are highly effective against $E$. coli (Brussow, 2005); decreasing intrauterine bacterial load is likely to reduce the severity of clinical disease (Sheldon et al., 2004); rapid clearance of phages from the circulatory system will not be a problem because intrauterine therapy is a viable option; and iatrogenic endotoxemia is unlikely with intrauterine administration of purified phage lysates.

We isolated environmental bacteriophages that caused lysis of E. coli isolates from uteri of postpartum dairy cows and tested the lytic activity of these bacteriophages to compose a broad-spectrum bacteriophage cocktail to control E. coli growth (Bicalho et al., 2010). The bacteriophage cocktail preparation showed remarkable antimicrobial activity against antimicrobial-multiresistant $E$. coli isolated from uteri of Holstein dairy cows (Table 3 ). Higher MOI (pfu:cfu ratios $>10^{2}$ ) should be tested in future studies in vitro to establish ratios that completely inhibit bacterial growth during longer periods. Additionally, the E. coli isolates used in this study were not phylogenetically diverse because 
PHAGE COCKTAIL

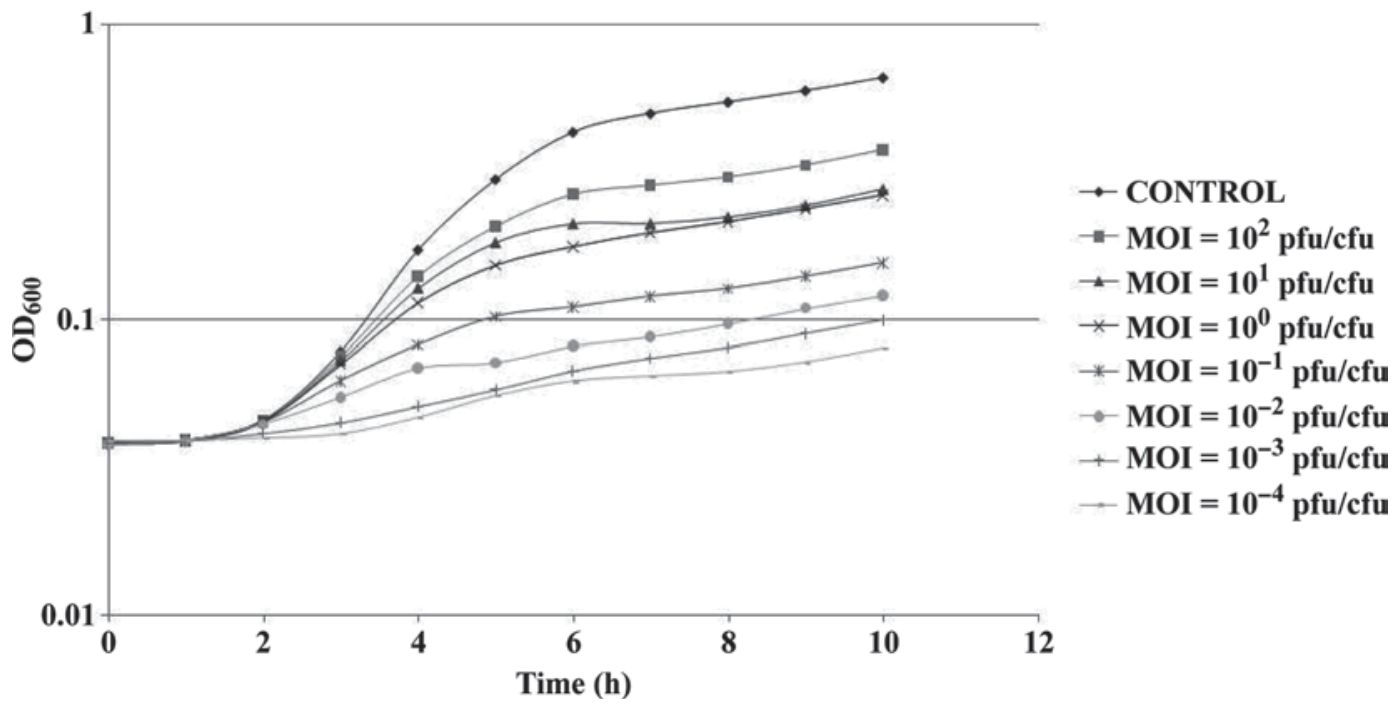

Figure 3. Mean effect of bacteriophage cocktail on growth curve of all 57 Escherichia coli isolates. Escherichia coli were isolated from uterine secretions of postpartum Holstein dairy cows. $\mathrm{MOI}=$ multiplicities of infections; $\mathrm{OD}_{600}=$ optical density at $600 \mathrm{~nm}$.

all isolates belonged to B1 group. Bacteriophages are known for their host specificity (Brussow, 2005) and, therefore, it is possible that the phage cocktail used in this study will not have similar antimicrobial characteristics when a different population of $E$. coli isolates is tested. Genetic profile of these phages was assessed (Bicalho et al., 2010), and further characterization and purification should be performed before conducting animal trials.

The current study presented a short overview of antimicrobial resistance in $E$. coli isolated from uteri of postpartum dairy cows. In addition, it demonstrated that a bacteriophage cocktail was effective at inhibiting $E$. coli growth in vitro and that it might be an attractive alternative to antibiotics for treatment and metaphylaxis of bovine metritis.

\section{CONCLUSIONS}

The findings of phenotypic characterization of antimicrobial resistance suggest that $E$. coli from uteri of dairy cows can be an important reservoir for antimicrobial resistance determinants. Therefore, the nonpathogenic $E$. coli isolates could be an important source of resistance genes to other bacteria that share the same environment. Only $1.25 \%$ of the isolates were resistant to ceftiofur. All isolates resistant to florfenicol were resistant to chloramphenicol and, because florfenicol was recently introduced into veterinary clinics, this finding suggests that the selection pressure of chloramphenicol, as well as other antimicrobials, may still have a relevant role in the emergence and dissemination of florfenicol resistance in E. coli. The bacteriophage cocktail had a notable capacity to inhibit the in vitro growth of $E$. coli isolates, and it might be an attractive alternative to conventional treatment of metritis by reducing $E$. coli in uteri of postpartum dairy cows, and, consequently the severity of clinical disease.

\section{REFERENCES}

Angulo, F. J., V. N. Nargund, and T. C. Chiller. 2004. Evidence of an association between use of anti-microbial agents in food animals and anti-microbial resistance among bacteria isolated from humans and the human health consequences of such resistance. J. Vet. Med. B Infect. Dis. Vet. Public Health 51:374-379.

Arcangioli, M. A., S. Leroy-Setrin, J. L. Martel, and E. ChaslusDancla. 2000. Evolution of chloramphenicol resistance, with emergence of cross-resistance to florfenicol, in bovine Salmonella typhimurium strains implicates definitive phage type (DT) 104. J. Med. Microbiol. 49:103-110.

Azawi, O. I. 2008. Postpartum uterine infection in cattle. Anim. Reprod. Sci. 105:187-208.

Bennett, P. M. 2008. Plasmid encoded antibiotic resistance: Acquisition and transfer of antibiotic resistance genes in bacteria. Br. J. Pharmacol. 153(Suppl. 1):S347-S357.

Bicalho, R. C., T. M. A. Santos, R. O. Gilbert, L. S. Caixeta, L. M. Teixeira, M. L. S. Bicalho, and V. S. Machado. 2010. Susceptibility of Escherichia coli isolated from uteri of postpartum dairy cows to antibiotic and environmental bacteriophages. Part I: Isolation and lytic activity estimation of bacteriophages. J. Dairy Sci. 93:93104.

Biswas, B., S. Adhya, P. Washart, B. Paul, A. N. Trostel, B. Powell, R. Carlton, and C. R. Merril. 2002. Bacteriophage therapy rescues mice bacteremic from a clinical isolate of vancomycin-resistant Enterococcus faecium. Infect. Immun. 70:204-210.

Bondurant, R. H. 1999. Inflammation in the bovine female reproductive tract. J. Anim. Sci. 77(Suppl. 2):101-110.

Borsberry, S., and H. Dobson. 1989. Periparturient diseases and their effect on reproductive performance in five dairy herds. Vet. Rec. 124:217-219. 
Bradford, P. A., P. J. Petersen, I. M. Fingerman, and D. G. White. 1999. Characterization of expanded-spectrum cephalosporin resistance in $E$. coli isolates associated with bovine calf diarrhoeal disease. J. Antimicrob. Chemother. 44:607-610.

Brussow, H. 2005. Phage therapy: The Escherichia coli experience. Microbiology 151:2133-2140.

Callaway, T. R., T. S. Edrington, A. D. Brabban, R. C. Anderson, M. L. Rossman, M. J. Engler, M. A. Carr, K. J. Genovese, J. E. Keen, M. L. Looper, E. M. Kutter, and D. J. Nisbet. 2008. Bacteriophage isolated from feedlot cattle can reduce Escherichia coli $\mathrm{O} 157: \mathrm{H} 7$ populations in ruminant gastrointestinal tracts. Foodborne Pathog. Dis. 5:183-191.

CDC. 2006. Action plan-The focus areas: IV. Product development http://www.cdc.gov/drugresistance/actionplan/html/product. htm Accessed Mar. 8, 2009.

Clermont, O., S. Bonacorsi, and E. Bingen. 2000. Rapid and simple determination of the Escherichia coli phylogenetic group. Appl. Environ. Microbiol. 66:4555-4558.

CLSI. 2008. Performance Standards for Antimicrobial Disk and Dilution Susceptibility Test for Bacteria Isolated from Animals Approved Standard. 3rd edition. CLSI document M31-A3. Clinical and Laboratory Standards Institute, Wayne, PA.

Dohmen, M. J. W., K. Joop, A. Sturk, P. E. J. Bols, and J. A. C. M. Lohuis. 2000. Relationship between intra-uterine bacterial contamination, endotoxin levels and the development of endometritis in postpartum cows with dystocia or retained placenta. Theriogenology 54:1019-1032.

Fey, P. D., T. J. Safranek, M. E. Rupp, E. F. Dunne, E. Ribot, P. C. Iwen, P. A. Bradford, F. J. Angulo, and S. H. Hinrichs. 2000 Ceftriaxone-resistant Salmonella infection acquired by a child from cattle. N. Engl. J. Med. 342:1242-1249.

Gilbert, R. O., S. T. Shin, C. L. Guard, H. N. Erb, and M. Frajblat. 2005. Prevalence of endometritis and its effects on reproductive performance of dairy cows. Theriogenology 64:1879-1888.

Gilmore, A. 1986. Chloramphenicol and the politics of health. Can. Med. Assoc. J. 134:423, 426-428, 433-435.

Livermore, D. M. 1995. Beta-lactamases in laboratory and clinical resistance. Clin. Microbiol. Rev. 8:557-584.

Maidhof, H., B. Guerra, S. Abbas, H. M. Elsheikha, T. S. Whittam, and L. Beutin. 2002. A multiresistant clone of shiga toxin-producing Escherichia coli O118:H16 is spread in cattle and humans over different European countries. Appl. Environ. Microbiol. 68:58345842 .

Matsuzaki, S., M. Yasuda, H. Nishikawa, M. Kuroda, T. Ujihara, T. Shuin, Y. Shen, Z. Jin, S. Fujimoto, M. D. Nasimuzzaman, H. Wakiguchi, S. Sugihara, T. Sugiura, S. Koda, A. Muraoka, and S. Imai. 2003. Experimental protection of mice against lethal Staphylococcus aureus infection by novel bacteriophage phi MR11. J. Infect. Dis. 187:613-624.

Melendez, P., J. McHale, J. Bartolome, L. F. Archbald, and G. A. Donovan. 2004. Uterine involution and fertility of Holstein cows subsequent to early postpartum $\mathrm{PGF} 2_{\alpha}$ treatment for acute puerperal metritis. J. Dairy Sci. 87:3238-3246.

Moreira, M. A., J. A. Oliveira, L. M. Teixeira, and C. A. Moraes. 2005. Detection of a chloramphenicol efflux system in Escherichia coli isolated from poultry carcass. Vet. Microbiol. 109:75-81.

Picard, B., J. S. Garcia, S. Gouriou, P. Duriez, N. Brahimi, E. Bingen, J. Elion, and E. Denamur. 1999. The link between phylogeny and virulence in Escherichia coli extraintestinal infection. Infect. Immun. 67:546-553.

Picard, B., and P. Goullet. 1988. Correlation between electrophoretic types B1 and B2 of carboxylesterase B and host-dependent factors in Escherichia coli septicaemia. Epidemiol. Infect. 100:51-61.

Sambrook, J., and D. W. Russell. 2001. Molecular Cloning: A Laboratory Manual. 3rd ed. Cold Spring Harbor Laboratory Press, Cold Spring Harbor, NY.

Sawant, A. A., N. V. Hegde, B. A. Straley, S. C. Donaldson, B. C. Love, S. J. Knabel, and B. M. Jayarao. 2007. Antimicrobial-resistant enteric bacteria from dairy cattle. Appl. Environ. Microbiol. 73:156-163.

Schwarz, S., C. Kehrenberg, B. Doublet, and A. Cloeckaert. 2004. Molecular basis of bacterial resistance to chloramphenicol and florfenicol. FEMS Microbiol. Rev. 28:519-542.

Settepani, J. A. 1984. The hazard of using chloramphenicol in food animals. J. Am. Vet. Med. Assoc. 184:930-931.

Sheldon, I. M., and H. Dobson. 2004. Postpartum uterine health in cattle. Anim. Reprod. Sci. 82-83:295-306.

Sheldon, I. M., D. E. Noakes, A. N. Rycroft, D. U. Pfeiffer, and H. Dobson. 2002. Influence of uterine bacterial contamination after parturition on ovarian dominant follicle selection and follicle growth and function in cattle. Reproduction 123:837-845.

Sheldon, I. M., A. N. Rycroft, and C. Zhou. 2004. Association between postpartum pyrexia and uterine bacterial infection in dairy cattle. Vet. Rec. 154:289-293.

Smith, J. L., P. M. Fratamico, and N. W. Gunther. 2007. Extraintestinal pathogenic Escherichia coli. Foodborne Pathog. Dis. 4:134-163.

Soothill, J. S. 1992. Treatment of experimental infections of mice with bacteriophages. J. Med. Microbiol. 37:258-261.

Tollefson, L., P. J. Fedorka-Cray, and F. J. Angulo. 1999. Public health aspects of antibiotic resistance monitoring in the USA. Acta Vet. Scand. Suppl. 92:67-75.

Tollefson, L., and M. A. Miller. 2000. Antibiotic use in food animals: Controlling the human health impact. J. AOAC Int. 83:245254.

USDA. 2005. National Antimicrobial Resistance Monitoring System, Escherichia coli-2005. Bacterial Epidemiology and Antimicrobial Resistance. http://www.ars.usda.gov/Business/ docs.htm?docid=6770. Accessed March 16, 2009.

Viscardi, M., A. G. Perugini, C. Auriemma, F. Capuano, S. Morabito, K. P. Kim, M. J. Loessner, and G. Iovane. 2008. Isolation and characterisation of two novel coliphages with high potential to control antibiotic-resistant pathogenic Escherichia coli (EHEC and EPEC). Int. J. Antimicrob. Agents 31:152-157.

Walsh, C. 2003. Where will new antibiotics come from? Nat. Rev. Microbiol. 1:65-70.

White, D. G., C. Hudson, J. J. Maurer, S. Ayers, S. Zhao, M. D. Lee, L. Bolton, T. Foley, and J. Sherwood. 2000. Characterization of chloramphenicol and florfenicol resistance in Escherichia coli associated with bovine diarrhea. J. Clin. Microbiol. 38:45934598.

Winokur, P. L., D. L. Vonstein, L. J. Hoffman, E. K. Uhlenhopp, and G. V. Doern. 2001. Evidence for transfer of CMY-2 AmpC beta-lactamase plasmids between Escherichia coli and Salmonella isolates from food animals and humans. Antimicrob. Agents Chemother. 45:2716-2722. 